\title{
Idea Generation in Technology-Supported Teams: A Multilevel Motivational Perspective
}

\author{
Sankara-Subramanian Srinivasan \\ University of Arkansas \\ ssrinivasan@,walton.uark.edu
}

\author{
Likoebe M. Maruping \\ University of Louisville \\ likoebe.maruping@louisville.edu
}

\author{
Lionel P. Robert \\ University of Michigan \\ lprobert@umich.edu
}

\begin{abstract}
In this research, we draw on multilevel theory to understand the interplay between team characteristics-team size and team dispersion-and individual goal striving in influencing individual idea generation performance. We conducted a laboratory study involving 185 individuals nested in 34 brainstorming teams and found that individual goal striving is a stronger predictor of individual idea generation performance in dispersed team contexts compared to co-located team contexts and in larger teams than in smaller teams. The implications of the findings for theory and practice are discussed.
\end{abstract}

\section{Introduction}

Organizations use teams to manage the increasingly complex business challenges facing them. This is because teams have better informational resources compared to individuals and, therefore, are well-suited for identifying solutions to complex problems [1, 2, 3, 4]. However, teams have also been found to be ineffective at drawing on the informational resources they possess $[5,6,7,8]$. In order to facilitate efforts to draw on this rich informational asset, organizations are investing heavily in collaboration technologies. Despite this deluge of investment, the effects of collaboration technologies on idea generation have been mixed (see [9] and [10]for examples) and our understanding of why this is the case remains quite limited.

Idea generation has been well-studied in the information systems (IS) and management literatures (See for example, [9, 10, 11]). Emphasis has been placed on understanding the team design $[9,12,13,14]$, team process $[15,16,17]$, and technology design $[18$, 19] factors that facilitate greater productivity in idea generation. In an effort to understand how to compose teams for effective idea generation, a significant proportion of the idea generation literature has focused on examining the effects of team design. Specifically, team size and team dispersion have been found to be the two aspects of team design that most consistently affect productivity on idea generation tasks (see for example, $[9,10,20,21])$. Little is known about why these elements of team design have the effects that they do and the mechanism through which they operate.

In one of the first empirical studies to examine factors predicting individual idea generation performance in a technology-supported context, Valacich et al. [22] found that individual characteristics - most notably cognitive ability-play an important predictive role. They noted that the motivation of individuals was critical in translating cognitive ability into actual performance. More recently, Jung et al. [19] examined how interfaces could be designed to motivate individuals to be more productive in technology-supported idea generation environments. This research underscored the importance of individual motivation as a potential driver of individual contributions to idea generation tasks. However, they focused exclusively on the individual without incorporating the role of team context. Yet, recent research has underscored the importance of team context in facilitating individual motivation to pursue high performance in one's tasks $[23,24]$. Thus, there is an opportunity to integrate the extant literature on team size and team dispersionwhich constitute elements of team context-with this emerging literature on individual drivers of performance in technology-supported idea generation. Integration of these two literature streams is important because it can help us understand how team context alters the influence of individual attributes to influence overall team success $[23,24]$.

The purpose of this research is to address the theoretical gaps identified above by examining the mechanisms through which team size and team dispersion affect individual idea generation performance in technology-supported teams. We accomplish this by drawing on two theoretical perspectives: self-regulation theory and multilevel theory. Self-regulation theory is a motivational theory that explains how individuals manage their efforts to achieve specific objectives [23]. The theory has played an important role in differentiating high versus low performing individuals who are embedded in the same social context $[25,24]$ and can help us understand 
individual performance in idea generation in technology-supported contexts [19]. Using multilevel theory we connect the literature that has examined the effects of team size and team dispersion, exclusively at the team level, with motivational literature, at the individual level.

This research contributes to research on technology-supported idea generation by drawing on multilevel theory and examining the cross-level impacts of team size and team dispersion on individual performance in technology-supported idea generation. Second, we contribute to the literature by examining the mechanisms by which team size and team dispersion affect performance in technology-supported idea generation and thus we uncover the specific mechanisms that underlie this deceptively simple relationship [26]. Finally, we contribute to selfregulation theory by examining the context-dependent effects of motivation. This answers numerous calls for research that examines individual performance in context $[27,28]$.

\section{Multilevel research}

Multilevel research broadly refers to research that incorporates different levels of analysis [29, 30, 31]. Viewed through this lens, phenomena that unfold at one level of analysis can be reasonably expected to be shaped by characteristics of the higher level context in which they are embedded $[27,32,33]$. We adopt this view of multilevel research in this paper and focus on its implications for explicating cross-level relationships between individual task performance and the team context in which it occurs. We specify team dispersion and team size as two structural characteristics of teams that form an important part of the context in which individual team members are embedded. In examining the cross-level influences of these characteristics we treat them as elements of discrete context [27]. Johns refers to discrete context as "situational variables that influence behavior directly or moderate relationships between variables" [27 p. 393].

\section{Theory and hypothesis development}

Motivation is defined as the "internal forces that direct, energize, and sustain work-related effort" [25 p. 290]. There has been an increasing recognition of the importance of understanding motivation in teams as indicated by the growing body of research on the topic (see [34-36]). Research on individual motivation in team contexts is important because "teams constitute a proximal social environment influencing individuals at work" [25 p. 286], [34]. There is a rich stream of literature in social psychology involving small groups that has shown that groups can influence the motivation of their members (see [34] for a review). Groups have been shown to both positively and negatively impact individual motivation and, consequently, effort exertion. For instance, social loafing [9, 10] and free-riding behavior [35] surface when individuals work in a group setting because groups offer conditions conducive for individuals to lower the amount of effort they exert in contributing to the group's goal achievement. Also, groups can exert social influence that makes group members behave in conformance with group norms [36]. Much of the research on work motivation has focused on individual motivation without factoring in contextual influences [23].

Individual goal striving is a part of the individual motivational process [23] and refers to "regulation of effort during actual goal pursuit" [23], [25]. In a team context, goal striving relates to "a member's allocation of personal effort towards team goals" [24 p. 46] through the "self-regulation of effort" [25 p. 46]. The regulation reflected in goal striving involves "...modulation of thought, affect, behavior, or attention via deliberate or automated use of specific mechanisms and supportive metaskills" [37 p. 25]. Prior research [38, 39] has proposed self-monitoringbeing cognizant of one's actions and the effects it can have, and self-evaluation-comparing one's present progress/performance to the desired state as two of the mechanisms underlying goal striving. In studying the prior research findings on motivation, Kanfer and Heggestad [40] found that individuals engaged in goal striving used self-regulatory strategies to control the motivational process.

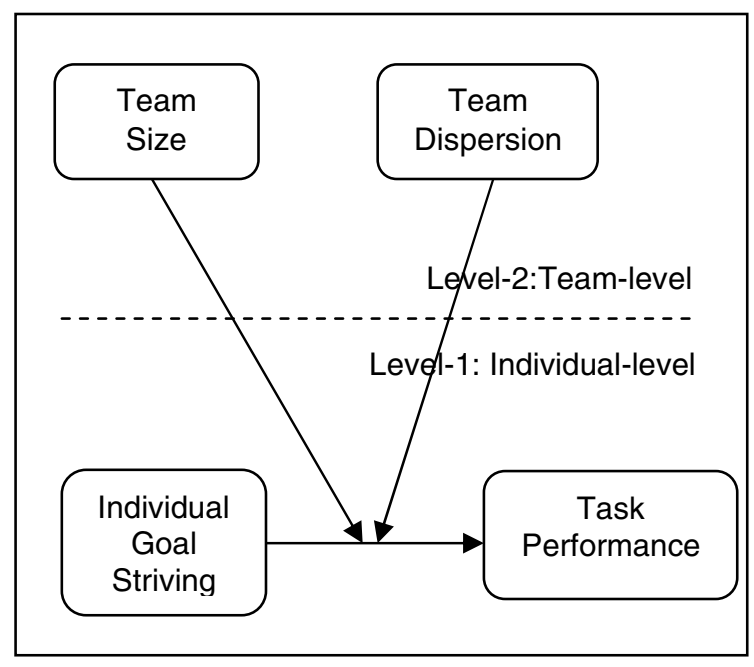

Figure 1. Research model 


\subsection{Individual goal striving and task performance}

We expect individual goal striving to positively influence individual idea generation performance. Research has shown goal striving and goal generation to be proximal determinants of task performance in teams [23, 41, 42]. In a study of simulated radar teams, Deshon and Colleagues [42] found that goal striving promoted higher performance at both the individual and team levels of analysis. Similarly, Chen et al. [41] found that goal striving positively influenced performance at both the individual and team levels of analysis. As such, goal striving has repeatedly been found to be the most salient antecedent in the motivational process when it comes to predicting individual performance within teams (for example, see [24]). This is because performance on activities such as idea generation in a brainstorming task tends to be dependent upon individuals' ability to channel the effort directed toward the task, i.e., via goal striving. In fact, prior research has shown that poor performers do not often differ from high performers in terms of individual ability as much as in their persistence at the task [38, 39].

Consequently, in the brainstorming context, individuals with higher goal striving will generate more ideas. Hence, we hypothesize that individual goal striving will lead to greater performance, measured in terms of number of ideas generated.

H1: Individual goal striving will have a positive influence on the number of ideas generated.

\subsection{Cross-level moderation by team size}

We expect team size to moderate the relationship between individual goal striving and individual task performance. Past research on social loafing shows that when team size increases it becomes difficult for individuals to maintain the same level of individual output. In fact, the original premise of social loafing, or reduction of individual performance within teams, is based on the reduction of individuals output in proportion to the increases in team size [43]. This effect has generally been attributed, in part, to the decreased responsibility individuals feel as size increases [9]. In such contexts, the ability of individuals to self-motivate and self-regulate becomes a key differentiator between high and low performers because large teams do not have the same social controls that would prompt an individual to exert effort toward pursuing team objectives. In contrast, in teams of smaller size, individuals are likely to be prompted to pursue team objectives because their inaction will otherwise be evident to their teammates. In such contexts, the social pressure is likely to be the key driver rather than the ability to self-motivate and selfregulate via goal striving.

In the case of technology-supported brainstorming teams, increases in team size can be particularly problematic for another reason. As size increases in brainstorming teams it becomes difficult to track the contributions of other team members. The complexity of this problem was highlighted by Heninger et al. [44]. They referred to a phenomenon called dual-task interference. Dual-task interference is the inability of individuals to process and contribute information at the same time. As team size increases in technology-supported teams it becomes difficult for individual members to monitor the output of team members while also contributing their own ideas. The natural tendency of individuals to reduce output as size increases coupled with dual-task interference creates conditions that make it difficult for individuals to maintain the same level of individual output as team size increases.

One way to ensure that individuals maintain their level of individual output as team size increases is to monitor and regulate their own behavior. As such goal striving should become more important to individual performance as team size increases. Team members will have to rely more on their individual goal striving to maintain their level of individual performance. Hence, we hypothesize

H2: Team size will moderate the relationship between goal striving and the number of ideas generated such that the relationship becomes stronger (more positive) with increasing team size.

\subsection{Cross-Level moderation by team dispersion}

The presence of others (as experienced in face-to-face co-location) can influence the behavior of individuals within a team $[45,10]$. The "visible proximity" of other team members can encourage individual team members to exert effort on behalf of the team's goals [10 p. 152]. Consequently, in colocated teams the normative social pressure exerted by the presence of others is a salient antecedent to individual performance within teams $[9,10]$. That is, the mere physical presence of others can prompt individual team members to work hard on their tasks so that they are not seen to be shirking their responsibility. However, when an individual is dispersed, the lack of social control and synergy created by the presence of their teammates is absent [9]. The lack of visibility and psychological proximity 
makes it difficult for individuals in dispersed settings to use the team as a source of affection and commitment [46].

We expect that when individuals are embedded in dispersed contexts, self-regulation (via goal striving) becomes more important to predicting individual task performance. In dispersed teams individual goal striving compensates for the lack of social pressure and aligns members' actions with the team's goals [22]. However, in a co-located context the individual's motivation is not as important a driver of individual performance compared to the pressure to conform resulting from the physical presence of other members. As such we would expect team dispersion to moderate the relationship between goal striving and task performance such that the relationship becomes stronger when teams are dispersed. Hence we hypothesize,

\section{H3: Team dispersion will moderate the relationship between goal striving and the number of ideas generated such that with increasing levels of team dispersion the relationship becomes stronger (more positive).}

\section{Methodology}

We performed a laboratory experiment to test our hypothesized relationships. One hundred and ninety two undergraduate business students from a medium-sized university in the southern United States participated in the study. A total of thirty four teams were formed using random assignment. Team size and team dispersion were manipulated in the study. Team size ranged from three to nine members, with more than sixty percent of members $(63.5 \%)$ assigned to teams of size six and larger. To operationalize dispersion, half of the teams were randomly assigned to a co-located setting, while members of the other half were physically dispersed in different rooms. About thirty five (35.4) percent of the participants were female. The average age of the participants was twenty one (21.45) years. Participants received extra course credit in exchange for participation in the study. The participants were given information about electronically registering for the various available study sessions, at a time convenient to them. As the participants walked in to the session for which they registered, they were randomly assigned to either a colocated or a dispersed condition of a certain size. Team members of the best performing team were offered the chance to win $\$ 20$ each. A total of one hundred and eighty five responses $(96.4 \%)$ were usable.

\subsection{Task}

We used an electronic decision making task that has been employed in prior IS research studies (see [9], [10] for example). The task required the student participants to play the role of board of directors of a US-based wine manufacturing firm facing problems (image related) associated with global expansion. The participants were asked to generate as many ideas as they could to help the firm improve its image. Subsequently the participants had to discuss and narrow down the list of generated ideas to six ideas from which they had to vote for one idea that they wanted to be recommended to the company's management. For the purpose of this paper, we specifically focus on the performance of the participants in the first stage of the study, idea generation, as idea generation is the first step to problem solving in organizational settings and corresponds to the "intelligence phase of decision making" [10 p.157]. Further, individual performance, which is the focus of this paper, is measurable only from the brainstorming stage.

\subsection{Experimental Setting}

The members assigned to the co-located condition met in a conference room. They were seated around a table, facing each other. All participants were given a networked computer which was used to input ideas during the task through the collaboration tool. Participants had to individually generate ideas using the tool. The ideas generated by each team member were displayed on each other's computer screen. There was also a large screen where all the ideas being generated were projected for all team members to see.

In contrast, members of teams in the dispersed condition were physically dispersed in different rooms. When there were more members than available rooms members were seated at different locations in a large training room with blinds all around that make it similar to a cubicle. Each member was given a networked computer, the task description, and procedure guidelines. The only difference between teams in the co-located condition and teams in the dispersed condition was the location of the members and the ability of the members to see each other faceto-face. Other than that, we followed the same procedure for teams in both conditions.

\subsection{Technology}

All teams involved in the experiment used

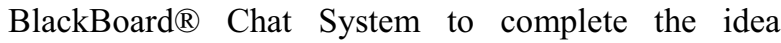
generation task. The chat system facilitates online 
collaboration and interaction using a standard webbrowser. Anonymity of the participating members was assured by using a unique identification code to identify members during the task in place of their real identity/name.

\subsection{Training}

All teams received identical training on the use of the collaboration tools. The trainer used an idea generation task (solving parking problem on campus) and walked the participants through the system. The training lasted for about 30 minutes and participants had the opportunity to ask questions about how to use the software. Participants were not aware of the specific research questions of the study, and were asked not to discuss the study or the training with others.

\subsection{Procedure}

Participants were welcomed and guided to a lab where they received their training on the group support system. Then members of the co-located teams were escorted to the conference room, while members of the dispersed teams are guided individually to a small room. All participants had to complete a pre-task survey that captured their demographic information. They had 15 minutes to read the task description. At the end of 15 minutes, participants were asked to generate as many ideas as possible. Members were able to read all of the ideas generated by their teammates. All teams in the experiment had 20 minutes to complete the brainstorming task. Subsequently they completed a questionnaire that captured their responses on specific aspects of interest to us. Finally, at the end of the experiment, participants were debriefed, thanked for their participation, and dismissed.

\subsection{Measures}

Goal Striving was measured, by adapting the scale from [41], on a seven point Likert scale. It was measured by the following items: I worked with my team members to help accomplish our task; I focused on coordinating the decision-making process with my team members; I focused my attention on how much time we had left and how many decisions we had yet to make; I communicated my thoughts and opinions to my team members when it was necessary; I provided feedback to my team members; I paid close attention to what I needed to do for each of the 6 decision issues; I monitored the progress we made toward reaching a consensus on the decisions. We controlled for Grade Point Average (GPA), age, gender, chat experience and task meaningfulness. We expected people with higher GPA to be more capable of coming up with more solutions to handle the challenge and so controlled for it. Similarly, we expected that age and gender could play a role in a creative task such as this and so controlled for them. Also, we expected that people who are lower on prior chat experience may be at a disadvantage when it comes to typing out ideas on a computer screen and so controlled for it. Finally, we didn't want the individuals' interest in the activity, as reflected by how meaningful they considered the task to be, to affect their performance. Hence, we controlled for task meaningfulness as well. The performance was measured at the individual level by counting the number of unique ideas that each member contributed.

\section{Results}

We present the results of our analysis by first giving an account of the preliminary analysis Table. 1 (see Appendix) presents the mean, standard deviation and correlations of the constructs in the model.

\subsection{Preliminary analysis}

The multi-item scale for goal striving was adapted from a previously validated scale [41]. It was the only multi-item scale in our study and it exhibited reliability greater than $0.70(0.89)$, thus meeting the threshold requirement. Table. 1 (See Appendix) provides the means, standard deviations, and correlation of the constructs employed in our research model. Consistent with prior research, team size is negatively correlated with number of ideas. Also, team dispersion is negatively correlated with the number of ideas generated, which is consistent with prior research. Goal striving positively correlated with performance measured by number of ideas.

\subsection{Model testing}

Table 2 (See Appendix) presents the results of our test of the proposed model. Considering the crosslevel effects at play in this multi-level model, we employed random coefficients modeling (RCM) using HLM 6.0, a RCM software package, for our analysis. The control variables, namely GPA, age, gender, chat experience and task meaningfulness were entered into the model in the first block. Goal striving was entered in the second block. Then, the team design factors, namely team size and team dispersion were entered in the third block. In the fourth block the interaction between elements in the second and third block, namely goal striving and team size, and goal striving 
and team dispersion were entered. Age had a positive influence on the number of ideas generated. Gender, chat experience and task meaningfulness did not have a statistically significant relationship with the number of ideas generated. GPA, age, gender, chat experience and task meaningfulness explained 6 percent of the variance in number of ideas generated. In the next stage, the motivational factor (goal striving) was entered in to the model. Consistent with Hypothesis 1, we find that goal striving leads to an increase in the number of ideas generated $\left(\gamma_{60}=.54, \mathrm{p}<.01\right)$. Model 4 included the interaction between goal striving and the team design variables in model 3. Hypothesis 2 predicted that team size will positively moderate the positive relationship between goal striving and number of ideas generated. From the results, we find that the direction of the relationship is as hypothesized. However, the result is not statistically significant $\left(\gamma_{01}=\right.$ $.19, \mathrm{p}=\mathrm{ns})$. Hypothesis 3 predicted that team dispersion will moderate the positive relationship between goal striving and number of ideas generated. From the results, we find that this is supported $\left(\gamma_{02}=\right.$ $.98, \mathrm{p}<.01)$.

\section{Discussion}

The objective of this research was to understand the performance of individuals in electronic brainstorming teams by considering individual motivation and team design factors. Specifically, we sought to understand how the performance of individuals is impacted by team input factors (that is, team design factors, namely - team size and team dispersion).We achieved this by integrating the selfregulation literature in to the idea generation literature. Further, we considered the multi-level nature of motivation and thus analyzed the moderating influence of team-level factors, namely team size and dispersion on the motivation to performance relationship. Very few studies of technology-supported brainstorming teams have explored the role of motivation in the team context. The current study is one of the first to explicitly integrate the motivational lens to understand performance in idea generation teams from a multilevel perspective. Using a lab-based study we tested our hypothesized model and we found that our model explains about $23 \%$ of the variance in individual performance, when performance is measured as the number of ideas contributed. We found that goal striving, or the regulation of one's effort, is far more critical in a dispersed team context than it is in a colocated team context. This has implications for practicing managers in terms of the need to pay attention to staffing dispersed teams with people who are naturally inclined toward regulation of their own task-related behavior.

This research makes several important theoretical contributions to the IS idea generation literature. We contributed to research on technologysupported idea generation by drawing on multilevel theory and examining the cross-level impacts of team size and team dispersion on individual performance in technology-supported idea generation. Second, we contributed to the literature by examining the mechanisms by which team size and team dispersion affect performance in technology-supported idea generation. By examining the chain from input (team size and dispersion) to outcome (individual and team performance) factoring in the interaction between input and processes (individual goal striving), we uncover the specific mechanisms that underlie this deceptively simple relationship [26]. Finally, we contribute to selfregulation theory by examining the context-dependent effects of motivation. Specifically, we incorporate the contextual effects of team size and team dispersion on the motivational drivers of individual performance in technology-supported idea generation. This answers numerous calls for research that examines individual performance in context $[27,28]$.

Our research also has some limitations which we list here. Although the usage of the validated experiment is a strength of this study, it is also has some limitations. Because the experiment was conducted in a controlled lab setting with student subjects, the findings may not necessarily generalize to a field setting. More research is required to test this aspect of the findings. Second, the nature of the task we employed is brainstorming which may not generalize to other task settings. There is a need to test our model in other settings, such as software development activity. Third, our sample was drawn from the population of undergraduate students enrolled at a US university. More research is required to test the robustness of the finding across cultures. Fourth, we used only number of ideas generated as a performance measure. An important aspect to consider is not only the number of ideas but also the quality of ideas. We think focusing on the number of high quality ideas along with the number of ideas would give much better insight into the performance impacts of motivation. We call on future research to consider this aspect of performance as well.

Future research should consider addressing some of these limitations and also analyze the bottomup relationship whereby individual motivation could impact the team performance. While "top-down effects are more prevalent, immediate and powerful relative to bottom-up effects" [ $24 \mathrm{p} .45]$, it is quite possible that bottom-up effects could throw additional light to 
understand dispersed team interactions and performance better.

\section{Conclusion}

In this research our aim was to add to the existing body of knowledge on idea generation (brainstorming) teams. While team size and dispersion have been established as antecedents to performance in idea generation teams, the additional mechanisms through which they impact performance has not been explored so far. This current study, considered the cross-level moderating effect of these factors on the goal striving to performance relationship. Interestingly, the study found that team dispersion positively moderates the relationship. That is with increasing dispersion the relationship becomes stronger. Thus this study, is one of the first in IS research to study motivation in teams using a multi-level lens. This study undertook a top-down model. Future studies that adopt a bottom up approach can throw more light on the specific mechanisms that predict performance in idea generation teams. Future research should consider some of these suggestions to further extend this line of research. Also, it would be interesting to apply other theories apart from motivation to understand performance in idea generating teams.

\section{References}

[1] L. Argote, and P. Ingram, "Knowledge Transfer: A Basis for Competitive Advantage in Firms," Organizational Behavior and Human Decision Processes, vol. 82, no. 1, 2000, pp. 150-169.

[2] A. R. Dennis, "Information Exchange and Use in Small Group Decision Making," Small Group Research, vol. 27, no. 4, 1996, p. 532.

[3] R. M. Grant, "Toward a Knowledge-Based Theory of the Firm,” Strategic Management Journal, vol. 17, no. 10, 1996 , pp. 109-122.

[4] D. R. Ilgen, J. R. Hollenbeck, M. Johnson, and D. Jundt, "Teams in Organizations: From Input-Process-Output Models to Imoi Models," Psychology, vol. 56, no. 1, 2005, p. 517.

[5] L. P. Robert Jr, A. R. Dennis, and M. K. Ahuja, "Social Capital and Knowledge Integration in Digitally Enabled Teams," Information Systems Research, vol. 19, no. 3, 2008, p. 314.

[6] G. Stasser, "The Uncertain Role of Unshared Information in Collective Choice," Shared cognition in organizations: the management of knowledge, 1999, p. 49.

[7] J. S. Valacich, A. R. Dennis, T. Connolly, and A. R. D. and T. C. Joseph S. Valacich, "Idea Generation in ComputerBased Groups: A New Ending to an Old Story," 1994 [Online]. Available: http://econpapers.repec.org/article/eeejobhdp/v_3a57_3ay_3a
1994 3ai 3a3 3ap 3a448-467.htm. [Accessed: 15-Jun2011].

[8] W. P. van Ginkel, and D. van Knippenberg, "Group information elaboration and group decision making: The role of shared task representations," Organizational Behavior and Human Decision Processes, vol. 105, no. 1, 2008, pp. 82-97. [9] O. A. Alnuaimi, L. P. Robert, and L. M. Maruping, "Team Size, Dispersion, and Social Loafing in TechnologySupported Teams: A Perspective on the Theory of Moral Disengagement," Journal of Management Information Systems, vol. 27, no. 1, 2010, pp. 203-230.

[10] L. Chidambaram, and L. L. Tung, "Is Out of Sight, Out of Mind? an Empirical Study of Social Loafing in Technology-Supported Groups," Information Systems Research, vol. 16, no. 2, 2005, p. 149.

[11] J. Fjermestad, and S. R. Hiltz, "An Assessment of Group Support Systems Experimental Research: Methodology and Results," Journal of Management Information Systems, vol. 15 , no. 3, 1998, pp. 7-149.

[12] A. R. Dennis, and J. S. Valacich, "Computer Brainstorms: More Heads Are Better Than One.," Journal of Applied Psychology, vol. 78, no. 4, 1993, p. 531.

[13] R. B. Gallupe, A. R. Dennis, W. H. Cooper, J. S. Valacich, L. M. Bastianutti, and J. F. Nunamaker Jr, "Electronic Brainstorming and Group Size," Academy of Management Journal, vol. 35, no. 2, 1992, pp. 350-369.

[14] J. S. Valacich, B. C. Wheeler, B. E. Mennecke, and R. Wachter, "The Effects of Numerical and Logical Group Size on Computer-Mediated Idea Generation," Organizational Behavior and Human Decision Processes, vol. 62, no. 3, 1995, pp. 318-329.

[15] A. R. Dennis, J. E. Aronson, W. G. Heninger, and E. D. Walker, "Structuring Time and Task in Electronic Brainstorming," MIS Quarterly, 1999, pp. 95-108.

[16] A. R. Dennis, J. S. Valacich, T. Connolly, and B. E. Wynne, "Process Structuring in Electronic Brainstorming," Information Systems Research, vol. 7, no. 2, 1996, p. 268.

[17] J. S. Valacich, and C. Schwenk, "Devil' s Advocacy and Dialectical Inquiry Effects on Face-to-Face and ComputerMediated Group Decision Making," Organizational Behavior and Human Decision Processes, vol. 63, no. 2, 1995, pp. 158-173.

[18] D. M. DeRosa, C. L. Smith, and D. A. Hantula, "The Medium Matters: Mining the Long-Promised Merit of Group Interaction in Creative Idea Generation Tasks in a MetaAnalysis of the Electronic Group Brainstorming Literature," Computers in Human Behavior, vol. 23, no. 3, 2007, pp. 1549-1581.

[19] J. H. Jung, C. Schneider, and J. Valacich, "Enhancing the Motivational Affordance of Information Systems: The Effects of Real-Time Performance Feedback and Goal Setting in Group Collaboration Environments," Management Science, vol. 56, no. 4, 2010, pp. 724-742.

[20] K. Burke, and L. Chidambaram, "How Much Bandwidth Is Enough? A Longitudinal Examination of Media Characteristics and Group Outcomes," MIS Quarterly, vol. 23, no. 4, 1999, pp. 557-579.

[21] R. Sharda, S. H. Barr, and J. C. McDonnell, "Decision Support System Effectiveness: A Review and an Empirical Test," Management Science, vol. 34, no. 2, 1988, pp. 139159. 
[22] J. S. Valacich, J. H. Jung, and C. A. Looney, "The Effects of Individual Cognitive Ability and Idea Stimulation on Idea-Generation Performance," Group Dynamics: Theory, Research, and Practice, vol. 10, no. 1, 2006, pp. 1-15.

[23] G. Chen, and R. Kanfer, "Towards a Systems Theory of Motivated Behavior in Work Teams," Research in Organizational Behavior: An Annual Series of Analytical Essays and Critical Reviews, vol. 27, 2006, pp. 223-267.

[24] G. Chen, R. Kanfer, R. P. DeShon, J. E. Mathieu, and S. W. J. Kozlowski, "The Motivating Potential of Teams: Test and Extension of Chen and Kanfer's (2006) Cross-Level Model of Motivation in Teams," Organizational Behavior and Human Decision Processes, vol. 110, no. 1, 2009, pp. 45-55.

[25] G. Chen, and C. I. Gogus, "Motivation in and of Work Teams: A Multilevel Perspective," Work Motivation: Past, Present, and Future, 2008, pp. 285-318.

[26] R. O. Briggs, and B. A. Reinig, "Bounded Ideation Theory," Journal of Management Information Systems, vol. 27, no. 1, 2010, pp. 123-144.

[27] G. Johns, "The Essential Impact of Context on Organizational Behavior," Academy of Management Review, vol. 31, no. 2, 2006, p. 386.

[28] D. M. Rousseau, and Y. Fried, "Location, Location, Location: Contextualizing Organizational Research," Journal of Organizational Behavior, vol. 22, no. 1, 2001, pp. 1-13.

[29] A. Burton-Jones, and M. J. Gallivan, "Toward a Deeper Understanding of System Usage in Organizations: A Multilevel Perspective," Management Information Systems Quarterly, vol. 31, no. 4, 2007, p. 657.

[30] S. W. J. Kozlowski, and K. J. Klein, "A Multilevel Approach to Theory and Research in Organizations: Contextual, Temporal, and Emergent Processes.," 2000.

[31] J. E. Mathieu, and G. Chen, "The Etiology of the Multilevel Paradigm in Management Research," Journal of Management, 2010.

[32] P. S. Goodman, Missing Organizational Linkages: Tools for Cross-Level Research. Sage Publications, Inc, 2000.

[33] G. Johns, "In Praise of Context," Journal of Organizational Behavior, vol. 22, no. 1, 2001, pp. 31-42.

[34] J. R. Hackman, "Group influences on individuals in organizations.," 1992.

[35] M. Olson, The Logic of Collective Action. Cambridge, 1965.
[36] D. C. Feldman, "The Development and Enforcement of Group Norms," Academy of Management Review, vol. 9, no. 1, 1984, pp. 47-53.

[37] P. Karoly, "Mechanisms of self-regulation: A systems view," Annual review of psychology, vol. 44, no. 1, 1993, pp. $23-52$.

[38] R. Kanfer, and P. L. Ackerman, "Motivation and Cognitive Abilities: An Integrative/Aptitude-Treatment Interaction Approach to Skill Acquisition," Journal of Applied Psychology, vol. 74, no. 4, 1989, pp. 657-690.

[39] R. Kanfer, and P. L. Ackerman, "A Self-Regulatory Skills Perspective to Reducing Cognitive Interference," Cognitive interference: Theories, methods, and findings, 1996, pp. 153-171.

[40] R. Kanfer, and E. D. Heggestad, "Motivational Traits and Skills: A Person-Centered Approach to Work Motivation," Research in organizational behavior, vol. 19, 1997, pp. 1-56.

[41] G. Chen, B. Thomas, and J. C. Wallace, "A Multilevel Examination of the Relationships Among Training Outcomes, Mediating Regulatory Processes, and Adaptive Performance.," Journal of Applied Psychology, vol. 90, no. 5, 2005, pp. 827-841.

[42] R. P. DeShon, S. W. J. Kozlowski, A. M. Schmidt, K. R. Milner, and D. Wiechmann, "A Multiple-Goal, Multilevel Model of Feedback Effects on the Regulation of Individual and Team Performance," Journal of Applied Psychology, vol. 89, no. 6, 2004, pp. 1035-1055.

[43] M. Ringelmann, "Research on animate sources of power: The work of man," Annales de l'Instuit National Agronomique, vol. 12, 1913, pp. 1-40.

[44] W. G. Heninger, A. R. Dennis, and K. M. N. Hilmer, "Research Note: Individual Cognition and Dual-Task Interference in Group Support Systems," Information Systems Research, vol. 17, no. 4, 2006, p. 415.

[45] B. Guerin, "Mere Presence Effects in Humans: A Review," Journal of Experimental Social Psychology, vol. 22, no. 1,1986 , pp. 38-77.

[46] G. Desanctis, and R. B. Gallupe, "A Foundation for the Study of Group Decision Support Systems," Management science, vol. 33, no. 5, 1987, pp. 589-609. 


\section{Appendix}

Table 1. Descriptive statistics and correlations $(\mathrm{N}=185)$

\begin{tabular}{|c|c|c|c|c|c|c|c|c|c|c|c|}
\hline Variables & Mean & SD & Reliability & 1 & 2 & 3 & 4 & 5 & 6 & 7 & 8 \\
\hline $\begin{array}{l}\text { 1. Number of } \\
\text { Ideas }\end{array}$ & 5.52 & 3.38 & N.A. & & & & & & & & \\
\hline $\begin{array}{l}\text { 2. Individual Goal } \\
\text { Striving }\end{array}$ & 5.65 & .86 & .89 & $.13^{\dagger}$ & & & & & & & \\
\hline 3. Team Size & 6.02 & 1.49 & N.A. & $-.28 "$ & -.24 & & & & & & \\
\hline $\begin{array}{l}\text { 4. Team } \\
\text { Dispersion }\end{array}$ & .50 & .50 & N.A. & -.22 & $.30^{*}$ & $-.15^{*}$ & & & & & \\
\hline 5. GPA & 3.23 & .48 & N.A. & -.11 & -.09 & $.22^{* *}$ & .05 & & & & \\
\hline 6. Age & 21.45 & 3.11 & N.A. & $.21^{\prime \prime}$ & .04 & -.12 & .08 & $-.22 "$ & & & \\
\hline 7. Gender & .36 & .48 & N.A. & -.02 & .06 & -.02 & .11 & .14 & -.06 & & \\
\hline $\begin{array}{l}\text { 8. Chat } \\
\text { Experience }\end{array}$ & 5.84 & .91 & N.A. & -.03 & .28 & -.02 & .03 & -.25 & -.10 & -.07 & \\
\hline $\begin{array}{l}\text { 9. Task } \\
\text { Meaningfulness }\end{array}$ & 4.27 & 1.33 & N.A. & .04 & $.46^{*}$ & -.04 & .14 & -.11 & .04 & -.03 & $.25^{*}$ \\
\hline
\end{tabular}

Notes:

1. Level-1 $\mathrm{n}=185$; Level-2 $\mathrm{n}=34$

2. **. Correlation is significant at the 0.01 level (2-tailed).

*. Correlation is significant at the 0.05 level (2-tailed).

$\dagger$. Correlation is significant at the 0.1 level (2-tailed).

3. GPA - Grade Point Average 
Table 2. HLM Model Predicting Performance $(\mathrm{N}=185)$

\begin{tabular}{|c|c|c|c|}
\hline & \multicolumn{3}{|c|}{ Number of ideas } \\
\hline Variables & 1 & 2 & 3 \\
\hline \multicolumn{4}{|c|}{ Block 1: Controls } \\
\hline GPA $\left(\gamma_{10}\right)$ & -.02 & .11 & .04 \\
\hline Age $\left(\mathrm{V}_{20}\right)$ & $.17^{*}$ & $.20^{*}$ & $.20^{*}$ \\
\hline Gender $\left(\mathrm{\gamma}_{30}\right)$ & -.07 & -.04 & .04 \\
\hline $\begin{array}{c}\text { Chat experience } \\
\left(y_{40}\right)\end{array}$ & -.21 & -.07 & -.06 \\
\hline $\begin{array}{c}\text { Task } \\
\text { meaningfulness } \\
\left(\mathrm{y}_{50}\right)\end{array}$ & .13 & .02 & .02 \\
\hline \multicolumn{4}{|c|}{ Block 2: Main effects (level-1) } \\
\hline Goal striving $\left(\mathrm{V}_{60}\right)$ & & $.54^{* *}$ & $.49^{\star}$ \\
\hline \multicolumn{4}{|c|}{ Block 3: Main Effects (level-2) } \\
\hline Team size $\left(\mathrm{V}_{01}\right)$ & & $1.70^{\star \star \star}$ & $-1.71^{\star *}$ \\
\hline $\begin{array}{c}\text { Team dispersion } \\
\left(\mathrm{Y}_{02}\right)\end{array}$ & & $-.73^{\star \star}$ & $-.72^{\star \star \star}$ \\
\hline \multicolumn{4}{|c|}{ Block 4: Cross-level Interactions } \\
\hline $\begin{array}{c}\text { Team size } \mathrm{x} \text { goal } \\
\text { striving }\end{array}$ & & & .19 \\
\hline $\begin{array}{c}\text { Team dispersion } \\
\mathrm{x} \text { goal striving }\end{array}$ & & & $.98^{\star \star}$ \\
\hline Deviance & 945.56 & 925.58 & 923.31 \\
\hline$x^{2}$ & $82.19^{\star \star \star}$ & $55.64^{\star \star}$ & $50.10^{\star \star}$ \\
\hline $\mathrm{R}^{2}$ & $.06^{\dagger}$ & $.21^{\star \star \star}$ & $.23^{\star \star \star}$ \\
\hline$\Delta \mathrm{R}^{2}$ & & .15 & .02 \\
\hline
\end{tabular}

Notes:

1. Level-1 $n=185$; Level- $2 \mathrm{n}=34$

2. ${ }^{* * *}$. Significant at the 0.001 level (2-tailed).

**. Significant at the 0.01 level (2-tailed).

*. Significant at the 0.05 level (2-tailed).

$\dagger$. Significant at the 0.1 level (2-tailed). 